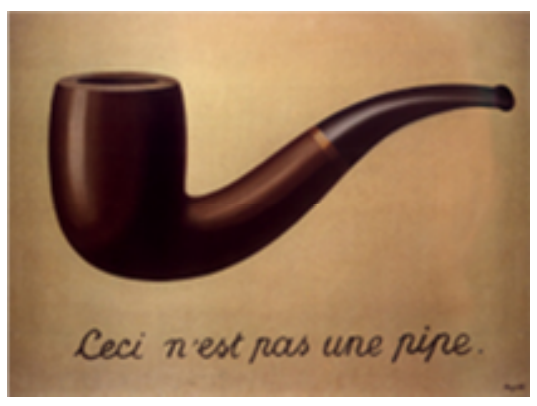

René Magritte

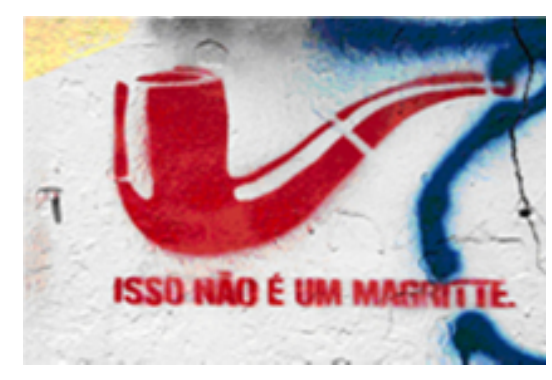

Grafite anônimo

\title{
Hibridismo formal: uma questão gráfica ou conceitual?
}

\section{Maurício Silva Gino}

O autor agradece aos componentes do Grupo de Estudos

de Metáforas e Analogias na Tecnologia,

na Educação e na Ciência - GEMATEC, do CEFET-MG,

e ao Núcleo de Fotografia da Escola de Design da UEMG.

Maurício Silva Gino é mestre em Tecnologia pelo CEFET-MG e doutorando em Ciência Animal pela UFMG. É professor do Departamento de Fotografia, Teatro e Cinema da Escola de Belas Artes da UFMG desde 2006.

\section{Resumo}

A partir de uma breve conceituação do termo "imagem", este trabalho busca apresentar uma discussão a respeito das possibilidades de hibridismo formal em representações gráficas. Uma possível conclusão a que se chega é que a constante transformação do pensamento humano amplia 
infinitamente as possibilidades de leitura e, conseqüentemente, de criação de novos registros.

Palavras-chave: imagem, cognição, hibridismo formal.

Eventualmente, autores de textos sobre imagens deparam-se com uma questão fundamental: como separar grafismos do seu sentido, uma vez que ambos podem ser designados pelo mesmo termo imagem? Na verdade, tal discussão não é recente, tendo início na primeira metade do século XX e contando com importantes provocações de artistas como René Magritte e Marcel Duchamp, bem como com as colaborações de autores ligados à fenomenologia, como Jean-Paul sartre. Para este último,

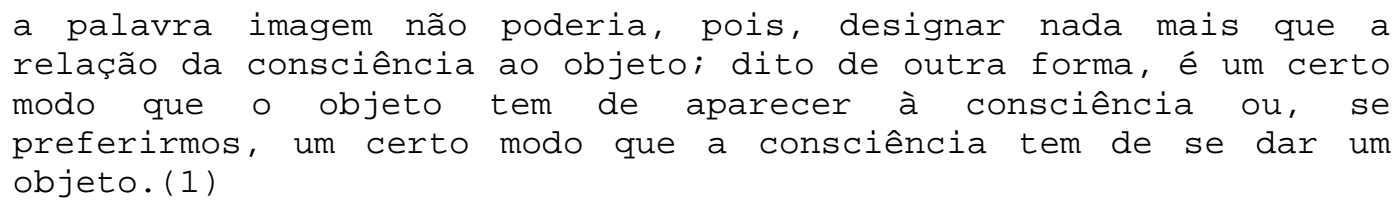

Para ele, o termo "imagem" deveria designar, simplesmente, um tipo específico de consciência que se tem sobre determinado objeto não sendo, portanto, o objeto em si ou as representações desse objeto criadas pelo homem. Dessa forma, as imagens não poderiam ter uma forma física, uma vez que estão restritas à imaterialidade da consciência.

Assim, em decorrência dos vários significados para o termo "imagem", e com o objetivo de permitir uma discussão sobre as possibilidades de leitura a partir do hibridismo formal, optou-se neste texto pelo emprego dos termos "registro gráfico" para designar objetos produzidos pela expressão humana, e "significado", para designar o sentido que esses registros são capazes de provocar no leitor/espectador.

Nesse contexto, uma questão apresenta-se como grande tema a ser discutido: quantos textos se consegue ler no hibridismo formal?

Um primeiro problema é a delimitação do que significa hibridismo formal. Uma possível interpretação desse termo é a mescla de diferentes formas de gráficos como, por exemplo, a representação por meio do desenho ou da pintura em associação ao registro gráfico das palavras pela escrita.

Nesse ponto, a obra de Magritte (Figura 1) é especialmente emblemática, uma vez que a simples representação pictórica de um cachimbo despertaria no observador um determinado 
significado, mas quando associada a um texto adquire um outro sentido aparentemente contraditório.

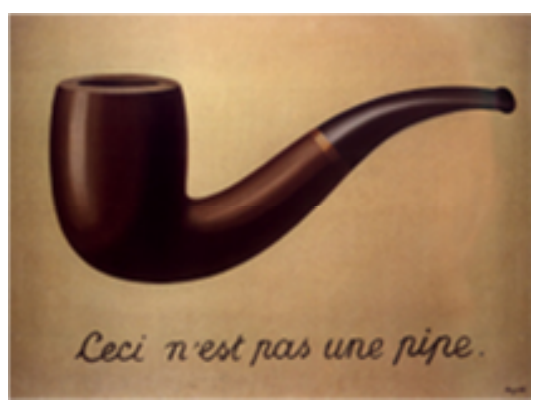

FIGURA 1: MAGRITTE, René. A traição das imagens. 1928-9. Óleo sobre tela. $60 \times 81 \mathrm{~cm}$. Los Angeles County Museum of Art, Los Angeles

Nessa obra, Magritte pinta realisticamente um cachimbo e em seguida provoca seu observador ao afirmar, em outras palavras, que não se trata de um cachimbo, mas de uma pintura. Esse significado só pode ser alcançado pelo hibridismo gráfico presente na obra.

Outra possibilidade de leitura para essa questão é o hibridismo no processo de produção do registro gráfico, o que traz consigo um impacto na sua forma de apresentação. Nesse sentido, uma obra que foi concebida originalmente como um registro pictórico único, como o Magritte original a que se referiu acima, pode em seguida ser reproduzida por meios fotoquímicos e posteriormente digitalizada e disponibilizada em ambientes virtuais e eletrônicos, como nesta versão.

Assim, o registro gráfico original de Magritte difere muito de seu análogo híbrido e reprodutível que aqui, neste contexto, assume outras possibilidades de leitura decorrentes especialmente da ampliação do seu acesso.

No entanto, uma interpretação que talvez seja ainda mais instigante para a questão é o poder que os registros gráficos possuem de nos remeter a outros registros, ampliando infinitamente as possibilidades de leituras e de significados.

Assim, quando se depara com um registro como o da figura 2, o espectador é convidado a retomar os significados apreendidos diante da obra de Magritte, sem o que este registro perderia parte do sentido buscado por seu desconhecido autor. Dessa forma, para compreender o significado pretendido, é necessário que o espectador tenha um mínimo de conhecimento sobre a obra de Magritte, bem como o contexto em que ela se insere. 


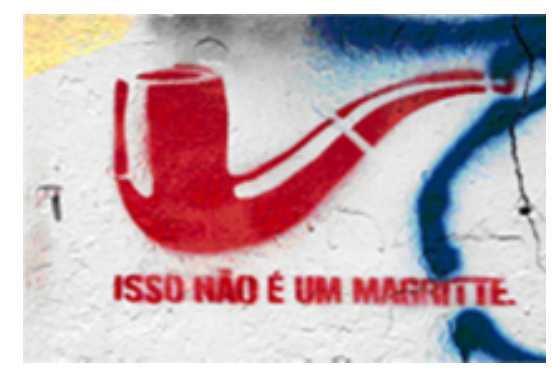

FIGURA 2: GINO, Maurício. Registro fotográfico de grafismo em parede do antigo prédio da Escola de Design da UEMG, com referência à obra $A$ traição das imagens, de René Magritte.

Talvez o surgimento do registro representado na figura 2 tenha sido fruto da transformação do pensamento humano. Como consequiência, tal transformação amplia constantemente as possibilidades de leitura e permite a criação de novos registros por diversos meios e em diferentes suportes.

Nesse ponto, contribuições de autores como Turner e Lakoff são especialmente importantes. Para os autores da linha cognitivista da lingüística, a leitura se dá por mapeamentos conceituais, sendo que o processo de compreensão ocorre por meio de mecanismos metafóricos baseados em conhecimentos prévios e experiências corpóreas. Assim, realiza-se pelo leitor/observador um verdadeiro hibridismo conceitual que possibilita novas leituras a partir de cada registro gráfico que constantemente surge.

Retomando a questão inicialmente proposta, conclui-se que, em quaisquer circunstâncias, a expressão do pensamento humano parece demonstrar que as possibilidades de leitura a partir do hibridismo formal aumentam infinitamente a partir de uma única obra, podendo se refletir numa interminável rede de manifestações e registros.

\section{Abstract}

From a short conceptualization of the term "image", this work aims to demonstrate a discussion about the possibilities of formal hybridism in graphic representations. A possible conclusion we can get is that the constant transformation of the human thought extends infinitely the possibilities of reading and, consequently, the creation of new records.

Key-words: image, cognition, formal hybridism.

\section{Nota}

(1) SARTRE, 1996. p. 19. 
Txt: Leituras Transdisciplinares de Telas e Textos, Belo Horizonte, v.3, n.5, p.75-79, 2007

\section{Bibliografia}

FAUCONNIER, Gilles, TURNER, Mark. The way we think: conceptual blending and the mind's hidden complexities. New York: Perseus Books Group, 2002.

LAKOFF, George, JOHNSON, Mark. Metáforas da vida cotidiana. Campinas: EDUC - Editora da PUC-SP / Mercado das Letras Edições, 2002.

MAGRITTE, René. A traição das imagens. In: o livro da arte. São Paulo: Livraria Martins Fontes Editora Ltda, 1996.

SARTRE, Jean-Paul. O imaginário. São Paulo: Ática, 1996. 